\title{
Cumulative trauma disorders and carpal tunnel syndrome: Sorting out the confusion
}

James Mahoney MD FRCSC

Division of Plastic Surgery, St Michael's Hospital, University of Toronto, Toronto, Ontario

J Mahoney. Cumulative trauma disorders and carpal tunnel syndrome: Sorting out the confusion. Can J Plast Surg 1995;3(4):185-189. Chronic work injury will be implicated as a cause of upper extremity musculoskeletal disorders in increasing numbers of patients. A wide variety of conditions, some with a specific diagnosis (eg, carpal tunnel syndrome) and a known response to treatment in contrast to more generalized disorders (eg, tendonitis) where the prognosis is uncertain form part of the spectrum. Experience has demonstrated that as the diagnosis becomes less specific, job related and emotional factors can significantly affect the patient's presentation, response to treatment and timing to return to work. Care needs to be exercised in implicating work in the etiology. General terms such as 'cumulative trauma disorder' and 'repetitive strain injury' need to be avoided.

Key Words: Carpel tunnel syndrome, Cumulative trauma disorders, Tendonitis

Troubles traumatiques cumulatifs et syndrome du tunnel carpien : de la lumière au bout du tunnel

RÉSUMÉ : Les blessures professionnelles chroniques risquent d'être de plus en plus incriminées dans les troubles musculo-squelettiques des membres supérieurs. Une grande variété de maladies, certaines accompagnées d'un diagnostic spécifique (par ex. syndrome du tunnel carpien) et une réponse connue au traitement, par opposition à des troubles de type plus généralisés (dont le pronostic reste incertain). Selon l'expérience, à mesure que le diagnostic se fait moins spécifique, des facteurs liés au travail et aux émotions peuvent affecter de façon significative le tableau clinique, la réponse au traitement et le moment du retour au travail. Les soins doivent donc être établis en fonction du poste de travail et de l'étiologie. Les thèmes généraux comme $<<$ traumatismes cumulatifs $>>$ et $<<$ blessures causées par des gestes répétitifs $>>$ sont à éviter. 


\section{PERSONAL USE ONTY DO NOT COPY}

The performance of frequent, forceful or awkward activities on an improperly positioned upper extremity creating stress are implicated in the development of diverse musculoskeletal disorders affecting the upper limb. They have been broadly grouped as 'cumulative trauma disorders' (CTDs) and are defined as disorders of the nerves, muscles, tendons and bones that are precipitated or aggravated by repeated exertions or movement $(1,2)$. It is suggested that they account for more than $50 \%$ of all occupational illnesses in the USA today (3) and in some states the frequency is alarming (4).

Injuries of the upper extremity may be classified as acute or chronic. 'Acute' injuries occur suddenly, ie, during a single supramaximal load event, accident or sudden change in pattern of use. Cumulative trauma disorders on the other hand are 'chronic' injuries and are suggested to develop gradually over a long period of time from overactivity exceeding the physical limit of tissue, perhaps as a result of heavy load, high frequency or rapidity resulting in repeated physical stress. The same work task will not produce the problem in everyone (5). Different types of manual work have been inferred as the source of chronic injury (Table 1) on the basis of an increased frequency of these disorders, most involving rapid forceful hand movements with wrist flexion and rotation. A pathologic clinical condition is produced that results in persistent symptoms and signs of a localized or diffuse nature. The role of work activity as the most important factor in causation as opposed to being coincidental or an aggravating factor continues to be controversial and the etiology remains to be defined. Similar conditions are recognized in sports related injuries and in musicians where overuse is easier to understand due to the specific repetitive activity involved.

TABLE 1: Occupations associated with an increased frquency of upper limb disorders affecting the upper extremity

\section{Disorder}

Tenosynovitis

Wrist tendonitis

De Quervain's disorder

Trigger finger

Epicondylitis

Carpal tunnel syndrome

Ulnar nerve and elbow

(cubital tunnel)

Vibration syndrome
Job

Food packer, buffer/grinder, cashier, data entry, musician

Assembler, packager, meat packer, keyboard operator

Sewer, cutter, packer, electronic assembler

Labeller

Musician, construction, butcher, electrician

Butcher, meat packer, assembly, postal worker, sewing, rock driller, cake decorator, grocery checker

Glass cutter, telephone operator

Forestry, chipper/grinder, rock drilling, jack hammer

Modified from Rempel (3)

The terminology concerning these disorders is extremely confusing. Many forms of occupational arm pain have been suggested to be interrelated, including myofascial pain disorders, chronic pain syndrome, cervical spondylosis, thoracic outlet syndrome and other nerve compression syndromes $(1,6)$. Some authors stress the need to be 
specific. Lockwood (7) defines an 'overuse syndrome' as an injury in musicians caused by the cumulative effect on tissues from repeated physical stress that exceeds physiologic limits but differentiates localized disorders such as tendonitis, tenosynovitis and peritendonitis crepitans (intersection syndrome) (8). Stern separates an 'overuse syndrome' from more specific disorders, such as tendonitis. He identifies the response to rest as the key component in overuse and states that surgical intervention is not indicated (9).

\section{CONTRIBUTING FACTORS}

Present social values affect the frequency and presentation of these problems. In general, although people are healthier they do not necessarily feel that way, even though physical and mental health is increasingly emphasized. Individuals are bothered more by trivial symptoms and disabled more by minor ailments than before. Pain that is believed to be treatable is thereby unnecessary but can hurt more than pain that is unavoidable and inevitable (10). Society has become more accepting of injury and disability and feels that compensation is increasingly justified. For the individual, work disability is associated with helplessness and dependency, and can be combined with a fear of jeopardizing the compensation claim (11). Various factors such as emotional, substance abuse and family environment can amplify body symptoms, playing a role in the presentation of the problem and the response to treatment.

Injury, whether or not related to work, can predispose to difficulty when followed by repetitive stress to the injured area. Substance abuse can affect the patient and the response to disability. A sports or exercise-induced injury, not work related, may only become evident by the work task.

Work skills (skilled versus unskilled), manual requirements (manual versus sedentary), language barrier, education level and financial remuneration will influence the patient's presentation and response to treatment. The job, company, industry and union are all important. Some patients may not like their job, be approaching retirement or feel threatened and will respond negatively to a physical complaint or lack motivation in their desire to return to work. Alternative financial support by Workman's

Compensation or litigation in the presence of persisting symptoms for greater than six months represents a cycle which is difficult to break. The support of the employer during the period of work absence and especially when returning to work may significantly facilitate convalescence, eg, modified work.

\section{PATHOPHYSIOLOGY}

These disorders (CTDs) have focused on muscles, tendon units and nerve compression and are to be distinguished from muscle fatigue, occupational cramp and exertional compartment syndrome. Many are localized to the friction interface between tendon and soft tissue or the origin of the muscle group, ie, tenosynovitis, tendonitis and epicondylitis, although mechanical studies of tissues involved do not offer insight into the etiology of this problem (12).

Pathologic findings have been described in different tissue types with some of the specific disorders. In tendonitis, swelling around the tendon sheaths on magnetic resonance imaging (13) and metaplasia of the tendon sheath (14) may be present. In carpal tunnel syndrome diffuse swelling or synovitis (15) has been seen. Muscle overuse 
is associated with histological change (16). Vibration, a specific form of trauma, is associated with the development of nerve change $(17,18)$. Generalized forms of the CTDs have been compared to fibrositis, a psychosomatic disorder, and a model based on neurogenic pathways has been proposed (19).

\section{EPIDEMIOLOGY}

The highly repetitive nature of some occupations is suggested as the reason for the statistically increased incidence of these problems (3) in an ever increasing number of occupations, including dentists (20) and computer operators (21). Every manual occupation may be associated with such an entity. On the other hand, careful epidemiological analysis of the work relatedness of carpal tunnel syndrome, one of the most common hand problems implicated in a wide variety of occupations (22), has raised serious questions about the validity of implicating work in its etiology (23). A surveillance case definition for work related carpal tunnel syndrome has been developed to facilitate the collection of data using recognized symptoms and signs associated with work (Table 2) (24). A recent study from Katz (25) investigated the validation of the surveillance case definition and indicated that effective screening of CTS awaits improved diagnostic techniques.

\section{TABLE 2: Surveillance case definition for work related carpal tunnel syndrome}

\section{Symptoms \\ Paraesthesia \\ Hypaesthesia \\ Pain \\ Numbness}

Physical findings

Tinel's sign

Positive Phalen's test

Diminished sensation to pin prick

\section{Electrodiagnostic findings}

Evidence of work relatedness

(1) Frequent repetitive use of the same or similar movements of the hand or wrist on the affected side

(2) Regular tasks requiring the generation of high force by the hand on the affected side

(3) Regular sustained tasks requiring awkward hand positions on the affected side

(4) Regular use of vibrating hand tools

(5) Frequent or prolonged pressure over the wrist or base of the palm on the affected side

In a review of 54 articles evaluating work related carpal tunnel syndrome (23), three met the required criteria (26-28) and a causal relationship between repetitive forceful work and the development of carpal tunnel was demonstrated. However, even the best study was limited by the sensitivity and specificity of the diagnostic criteria for carpal tunnel syndrome. The need for careful experimental design and objective measurement is to be emphasized and the importance of objective measures in such studies is to be stressed (29). 


\title{
PREVENTION
}

In many of the jobs that have developed in recent years, the worker is required to carry out less stimulating repetitive jobs. Ergonomics is the study of work, equipment, procedures and their environment so that people can optimize their maximum performance. It is a multidisciplinary approach that adapts the man-made world to the worker. The frequency of certain problems and the factors in their development is initially determined. Alterations of the work task to minimize problem development, eg, tools, exercise, rest periods and work modifications, are possible solutions. Employers with small companies occasionally cannot provide the appropriate or recommended job modification, and incentive programs that encourage small businesses to improve as well as general surveillance for larger companies is important.

\section{DIAGNOSTIC AND TREATMENT CONSIDERATIONS}

It is the physician's role to establish a specific musculoskeletal diagnosis, treatment plan and prognosis with expected duration of time off work based on the history, examination and investigations. Pertinent history is listed in Table 3. In general, investigations are performed more frequently in the working patient to document and verify the diagnosis and when there is difficulty in making a specific diagnosis.

TABLE 3: Pertinent aspects in the history which can help is establishing possible work relatedness

\author{
Predisposing medical conditions \\ Diabetes thyroid \\ Arthritis \\ Pain \\ Localized versus diffuse \\ Radiation \\ Relationship to work \\ - Time \\ - Specific task \\ - Hand position \\ Work history \\ Detailed job type \\ Frequency, force, repetition, awkward \\ Vibration exposure \\ Nonoccupational history \\ Hand activity \\ Vibration exposure
}

Logically if the disorder is precipitated by work, a reduction of activity, ie, rest, will improve the symptoms. Splintage, modified work and even temporary work cessation is of benefit (6) and may be the sole method of treatment in patients with generalized disorders (30). Relaxation training, attention to posture, manipulation, electrotherapy, acupuncture, chiropractic and naturopathy have been suggested (31). 
Other modalities known to improve inflammation and swelling, such as alternating ice with heat, ultrasound followed by stretching and later by strengthening, may assist but not always (3). Medicinal agents such as nonsteroidal anti-inflammatory drugs, acetylsalicylic acid (ASA) and local injection of steroids (32) can be considered. Surgery can be recommended for failures of conservative treatment for a specific diagnosis with a high expectation of improvement, eg, carpal tunnel syndrome $(33,34)$.

When patients return to the original job, they have the same factors working on them once again and it is suggested carpal tunnel syndrome associated with physically strenuous activity has a poorer outcome when measured by the ability to return to previous work (35). Recommendations for permanent work modification may be necessary. Vibration exposure requires special mention (eg, jack hammers). It is associated with carpal tunnel syndrome $(18,36,37)$ but patients are not as responsive to treatment (38) requiring restriction from this form of harmful stimulation.

As the presentation is often clouded with diffuse findings affecting different anatomical areas or types of conditions, it is important to rule out generalized disorders of upper extremity function, eg, thoracic outlet, rheumatoid arthritis, cervical radiculopathy, syringomyelia. Assessment and treatment can be very difficult (39) and careful follow-up evaluation of the response to treatment can help to verify the diagnosis. Prognosis both with the improvement in symptoms and time off work should be discussed and documented. One should also be cognizant of the positive reinforcement to the patient when treatment is recommended.

The Australian experience of repetitive strain injury highlights the problem of a generalized diagnosis (40). In the 1980s Australia experienced an epidemic of patients complaining of symptoms affecting the upper limbs including weakness, paraesthesia, swelling and pain. The pain, although consistent in a given patient, was not consistent among different patients and did not conform to any known neurological pathway, anatomic structure or physiological pattern. There were no primary objective physical findings and there were no positive findings on investigation. The condition affected young to middle-aged, predominantly female employees engaged in low paying monotonous, low prestige occupations. Once the entity was described it spread and the incidence of this condition rapidly increased to approximately $30 \%$ of the work force. There were no data and no pathological description $(41,42)$. It stopped when the Workers' Compensation Board stopped paying. It is now felt that repetitive strain injury should be classified as a sociopolitical phenomena rather than a medical condition $(43,44)$. Similar complaints have been seen in other countries (39).

\section{SUMMARY}

Generalized terms such as cumulative trauma syndrome, disorder or injury, implicating work as the source of the condition, have created confusion and need to be avoided $(45,46)$. There are few well designed studies identifying occupations or tasks which carry a high incidence of musculoskeletal problems involving the upper extremity. Similarly, there is little information as to what job modifications are required to minimize their development, the most appropriate treatment or how to prevent the problem from recurring. Caution needs to be exercised before initiating any form of treatment if the diagnosis is not specific, especially if other significant factors are identified. 
At present, when one is confronted with a patient with a condition possibly related to work, one must have an awareness of the other personal, financial and job related factors as well as the general medical status which may affect the situation. One must not hesitate to use allied health care workers such as specialists, therapists, vocational counsellors, etc, when necessary. The recommended form of treatment and the ultimate desired outcome with the patient returning to work are dependent on their interaction. The tendency for these disorders to affect the whole patient and not just the upper limb should be remembered.

\section{REFERENCES}

1. Mosely LH, Kalafut RM, Levinson PD, Mokris SA. Cumulative trauma disorders and compression neuropathies of the upper extremities. In: Kasdan ML, ed. Occupational Hand and Upper Extremity Injuries. Philadelphia: Hanley \& Belfus, 1991.

2. Armstrong TJ. Cumulative trauma disorders of the upper limb and identification of work related factors. In: Millender LH, Louis DS, Simmons BP, eds. Occupational Disorders of the Upper Extremity. New York: Churchill Livingstone, 1992.

3. Rempel DM, Harrison RJ, Barnhart S. Work-related cumulative trauma disorders of the upper extremity. JAMA 1992;267:838-42.

4. Millender LH. Occupational disorders. The disease of the 90's. A challenge or a bane for hand surgeons. J Hand Surg 1992;17A:193-5.

5. Pitner MA. Pathophysiology of overuse injuries in the hand and wrist. Hand Clin 1990;6:355-64.

6. Hales TJ. Management of upper extremity cumulative trauma disorders. AAOHN 1992;40:118-27

7. Lockwood AH. Medical problems of musicians. N Engl J Med 1989;320:221-7.

8. Thompson AR, Plewes LW, Shaw EG. Peritendinitis crepitans and simple tenosynovitis: A clinical study of 544 cases in industry. Br J Indust Med 1951;8:150-60. 9. Stern PJ. Tendonitis, overuse syndromes and tendon injuries. Hand Clin 1990;6:46776.

10. Barsky A. Worried Sick. Toronto, Boston: Little Brown and Co, 1988.

11. Deves L, Spillane R. Occupational health. Stress and work organization in Australia. Int J Health Serv 1989;19:351-63.

12. Goldstein SA, Armstrong TJ, Chaffin DB, Mathews LS. Analysis of cumulative strain in tendons and tendon sheaths. J Biomechanics 1987;20:1-6.

13. Hug C, Huber H, Terrier F, et al. Detection of flexor tenosynovitis by magnetic resonance imaging: Its relationship to diurnal variation of symptoms. J Rheumatol 1991;18:1055-9.

14. Sampson SP, Badalamente MS, Hurst LC, Seidman J. Pathobiology of the human A1 pulley in trigger finger. J Hand Surg 1991;16:714-21.

15. Mesgarzadeh M, Schneck CD, Bonakdarpou A, et al. Carpal tunnel: MR Imaging.

Part II. Carpal tunnel syndrome. Radiology 1989;173:749-54.

16. Dennett X, Fry HJ. Overuse syndrome: A muscle biopsy study. Lancet 1991;i:905-8. 17. Savage R, Burke FD, Smith NJ, Hopper I. Carpal tunnel syndrome in association with vibration white finger. J Hand Surg 1990;15:100-3. 
18. Wieslander G, Norback D, Gothe CJ, Juhlin L. Carpal tunnel syndrome (CTS) and exposure to vibration, repetitive wrist movements, and heavy manual work: A casereferent study. Br J Industrial Med 1989;46:43-7.

19. Littlejohn GO. Fibrositis/fibromyalgia syndrome in the workplace. Rheum Dis Clin of NA 1989;15:45-59.

20. Milerad E, Ekenvall L. Symptoms of the neck and upper extremities in dentists.

Scand J Work Environ Health 1990;16:129-34.

21. Mirman MJ, Vonian VG. 'Mouse elbow': A new repetitive stress injury. J Am

Osteopath Assoc 1992;92:701.

22. Delgrosso I, Boillat MA. Carpal tunnel syndrome: Role of occupation. Int Arch Occup Environ Health 1991;63:267-70.

23. Stock SR. Workplace ergonomic factors and the development of musculoskeletal disorders of the neck and upper limbs: A meta-analysis. Am J Indust Med 1991;19:87107.

24. Cummings K, Maizlish N, Rudolph L, Dervin MPH, Ervin A. Current trends; Occupational disease surveillance, carpal tunnel syndrome. MMWR 1989;38:485-9. 25. Katz JN, Larson MG, Fossel AH, Liang MH. Validation of a surveillance case definition of carpal tunnel syndrome. Am J Public Health 1991;81:189-93.

26. Silverstein BA, Fine LJ, Armstrong TJ. Hand wrist cumulative trauma disorders in industry. Br J Indust Med 1986;43:779-84.

27. Nathan PA, Meadows KD, Doyle LS. Occupation as a risk factor for impaired sensory conduction of the median nerve at the carpal tunnel. J Hand Surg 1988;13B:16770.

28. Luopajarvi T, Kuorinka I, Virolainen M, Holmberg M. Prevalence of tenosynovitis and other injuries of the upper extremities in repetitive work. Scand J Work Environ Health 1979;5(Suppl 3):48-55.

29. Higgs P, Young VL, Seaton M, Edwards D, Feely C. Upper extremity impairment in workers performing repetitive tasks. Plast Reconstr Surg 1992;90:614-20.

30. Fry HJH. Overuse Syndrome, alias tenosynovitis/tendonitis. The terminology hoax. Plast Reconstr Surg 1986;78:414-7.

31. Thompson D, Rawlings AJ, Harrington JM. Repetition strain injuries. In: Harrington JM, ed. Recent Advances in Occupational Health. Edinburgh:Churchill Livingstone, 1987.

32. Harvey FJ, Harvey PM, Horsley MW. De Quervain's disease: surgical or nonsurgical treatment. J Hand Surg 1990;15A:83-7.

33. Omer GE Jr. Median nerve compression at the wrist. Hand Clin 1992;8:317-24.

34. Braun RM, Davidson K, Doehr S. Provocative testing in the diagnosis of dynamic carpal tunnel syndrome. J Hand Surg 1989;14:195-7.

35. Yu GZ, Firrell JC, Tsai TM. Preoperative factors and treatment outcome following carpal tunnel release. J Hand Surg 1992:17B:646-50.

36. Cannon LJ, Bernacki EJ, Walter SD. Personal and occupational factors associated with carpal tunnel syndrome. J Occup Med 1981;23:255-8.

37. Koskimies K, Farkkila M, Pyykko I, et al. Carpal tunnel syndrome in vibration disease. Br J Indust Med 1990;47:411-6. 
38. Hagberg M, Nystrom A, Zetterlund B. Recovery from symptoms after carpal tunnel syndrome surgery in males in relation to vibration exposure. J Hand Surgery 1991;16:6671.

39. Millender LH. Occupational disorders of the upper extremity. Orthopedic, psychosocial and legal implications. In: Millender LH, Louis D, Simmons B, eds. Occupational Disorders of the Upper Extremity. New York: Churchill Livingstone, 1992. 40. Ireland DC. The Australian experience with cumulative trauma disorders. In: Millender LH, Louis D, Simmons B, eds. Occupational Disorders of the Upper Extremity. New York: Churchill Livingstone, 1992.

41. Hadler NM. Work related disorders of the upper extremity. Part 1: Cumulative trauma disorders - a critical review. In: Hadler NM, Bunn WB, eds. Occupational Problems in Medical Practice. New York: Della Corte, 1990.

42. Owen ER. The search for the pathology of repetition strain injuries. J Occupational Health Safety -Aust and NZ 1985;1:237-41.

43. Reid J, Ewan C, Lowy E. Pilgrimage of pain: The illness experiences of women with repetitive strain injury and the search for credibility. Soc Sci Med 1991;32:601-12.

44. Meekosha H, Jakubowicz A. Women suffering RSI the hidden relations of gender, the labour process and medicine. J Occupational Health Safety -Aust and NZ 1986;2:390401.

45. Barton NJ, Hooper G, Noble J, Steel WM. Occupational causes of disorders in the upper limb. BMJ 1992;304:309-11.

46. Semple JC. Tenosynovitis, repetitive strain injury, cumulative trauma disorder and overuse. J Bone Joint Surg 1991;73:536-8. 